\title{
Heat Capacities of Nanostructured Wurtzite and Rock Salt ZnO: Challenges of ZnO Nano-Phase Diagram
}

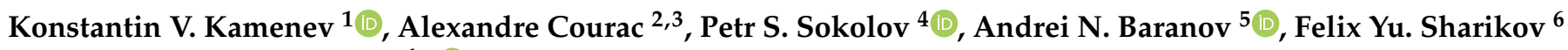 \\ and Vladimir L. Solozhenko ${ }^{4, *}$ \\ 1 School of Engineering and Centre for Science at Extreme Conditions, The University of Edinburgh, \\ Edinburgh EH9 3JZ, UK; k.kamenev@ed.ac.uk \\ 2 IMPMC, Sorbonne Université, CNRS, IRD, Muséum National d'Histoire Naturelle, 75005 Paris, France; \\ alexandre.courac@sorbonne-universite.fr \\ IUF, Institut Universitaire de France, 75005 Paris, France \\ LSPM-CNRS, Université Sorbonne Paris Nord, 93430 Villetaneuse, France; sokolov.petr@gmail.com \\ 5 Department of Chemistry, Moscow State University, 119991 Moscow, Russia; anb@inorg.chem.msu.ru \\ 6 Saint Petersburg Mining University, 199106 Saint Petersburg, Russia; felix101t@mail.ru \\ * Correspondence: vladimir.solozhenko@univ-paris13.fr
}

Citation: Kamenev, K.V.; Courac, A.; Sokolov, P.S.; Baranov, A.N.; Sharikov, F.Y..; Solozhenko, V.L. Heat Capacities of Nanostructured Wurtzite and Rock Salt ZnO: Challenges of ZnO Nano-Phase Diagram. Solids 2021, 2, 121-128. https://doi.org/10.3390/solids2010007

Received: 15 January 2021

Accepted: 20 February 2021

Published: 1 March 2021

Publisher's Note: MDPI stays neutral with regard to jurisdictional claims in published maps and institutional affiliations.

Copyright: (c) 2021 by the authors. Licensee MDPI, Basel, Switzerland. This article is an open access article distributed under the terms and conditions of the Creative Commons Attribution (CC BY) license (https:// creativecommons.org/licenses/by/ $4.0 /)$.
Abstract: Low-temperature heat capacities $\left(C_{p}\right)$ of nanostructured rock salt (rs- $\left.\mathrm{ZnO}\right)$ and wurtzite $(\mathrm{w}-\mathrm{ZnO})$ polymorphs of zinc oxide were measured in the $2-315 \mathrm{~K}$ temperature range. No significant influence of nanostructuring on $C_{p}$ of $\mathrm{w}-\mathrm{ZnO}$ has been observed. The measured $C_{p}$ of rock salt $\mathrm{ZnO}$ is lower than that of wurtzite $\mathrm{ZnO}$ below $100 \mathrm{~K}$ and is higher above this temperature. Using available thermodynamic data, we established that the equilibrium pressure between nanocrystalline $\mathrm{w}-\mathrm{ZnO}$ and rs- $\mathrm{ZnO}$ is close to $4.6 \mathrm{GPa}$ at $300 \mathrm{~K}$ (half as much as the onset pressure of direct phase transformation) and slightly changes with temperature up to $1000 \mathrm{~K}$.

Keywords: zinc oxide; heat capacity; nanostructure; phase diagram; high pressure

\section{Introduction}

The low-temperature heat capacity measurements are required for understanding the phase transformations and construction of low-temperature regions of the equilibrium pressure-temperature $(p-T)$ phase diagrams of elements and compounds, especially those important for mineralogy and explorative materials science (e.g., search for new materials under high pressure). At the same time, there are a number of problems that arise during the heat capacity measurements for analysis of equilibria at low temperatures and high pressures, such as

(1) the direct (adiabatic) measurements at ambient pressure are time-consuming, costly and most importantly require a significant amount of pure compound (typically hundreds of $\mu \mathrm{g}$ ), which makes explorative studies and study of phases recovered from very high pressures difficult (the pressure achievable in the laboratory is inversely proportional to the reaction volume);

(2) the results of typical Physical Property Measurement System (PPMS) measurements are limited in temperature $(\sim 350 \mathrm{~K})$ and can be influenced by systematic errors due to either poor thermal contact between the sample and the heater-thermometry platform; and/or between the grains in a polycrystalline sample (porosity, bad sintering, reduced inter-grain contacts, etc.);

(3) systematic errors can also arise due to the water present in two forms-(i) bound into crystal structure during the sample synthesis and (ii) absorbed from air due to the porosity of the sample;

(4) low thermal stability of some high-pressure phases (such as rs-ZnO) can limit possible measurements to low temperatures, while the data of interest may lay at much higher temperatures, so the reliable extrapolation procedures are required; and finally, 
(5) heat capacity data collection at high pressure remains rather exotic, very timeconsuming, available in arbitrary units and accessible only in a very narrow $p-T$ domain.

Usually, the construction of the phase diagrams at high enough temperatures (subject to the material and the pressure) is not considered be of importance once the reversible transitions between phases are observed. However, in some cases, even at high temperature, the crystallization of a new allotrope/polymorph is not reversible and, moreover, may occur outside the domain of thermodynamic stability (e.g., in the case of boron [1] or boron oxide [2]). The fundamental question of low-temperature stability can be hardly resolved without reliable low-temperature heat capacity data. Thus, the convincing thermodynamic analysis of materials at extended $p-T$ regions of the phase diagram is hardly possible without low-temperature data on $C_{p}$ at ambient pressure and without the methods of its extrapolation to high temperatures and high pressures.

Zinc oxide $\mathrm{ZnO}$ is a functional material that can be used both in industrial applications and for basic research in common $\mathrm{w}-\mathrm{ZnO}$ form [3], as well as in high-pressure $\mathrm{rs}-\mathrm{ZnO}$ form that is a material of interest for bright blue luminescence [4]. $\mathrm{rs}-\mathrm{ZnO}$ can be recovered at ambient conditions as individual (nanostructured) phase, up to the volume of $\sim 100 \mathrm{~mm}^{3}$ per individual high-pressure synthesis experiment $[4,5]$. The recovery of such a substantial sample volume allowed conducting the measurements of a wide range of physical properties - previously unavailable — such as, for example, the standard enthalpy of the $\mathrm{w}$-ZnO-to-rs-ZnO phase transformation $\Delta H(298.15 \mathrm{~K})=11.7 \pm 0.3 \mathrm{~kJ} \mathrm{~mol}^{-1}$ [6]. At the same time, the reported data should be taken with precaution, since the bulk samples with micro-sized grains are available only for $\mathrm{w}$-ZnO. Recent advances in the diverse synthetic routes of rs- $\mathrm{ZnO}$ materials [4] allowed us to obtain samples of chemical purity for reliable measurements of the heat capacities of both polymorphs for consistent side-by-side comparison.

Here, we report low-temperature heat capacities for both nanostructured $\mathrm{ZnO}$ polymorphs, consistent with observable phase transformation between polymorphs at high temperature (when pressure hysteresis between direct and inverse transformations becomes negligible). We established that the nanostructured samples contain the absorbed water (problem (3) of the list above), which is the major source of measurement errors that can be quite significant and should be considered when physical property measurements are conducted. Accounting for the exact amount of absorbed water (by using thermal gravimetric analysis) allowed us to obtain the accurate estimate of heat capacities and to evaluate the equilibrium pressure between $\mathrm{w}-\mathrm{ZnO}$ and $\mathrm{rs}-\mathrm{ZnO}$ polymorphs at high pressure and room temperature. No significant impact of nanostructuring on heat capacity has been observed for $\mathrm{w}-\mathrm{ZnO}$.

\section{Experimental Section}

The rs- $\mathrm{ZnO}$ sample purity was of primary concern for our work. In fact, $\mathrm{rs}-\mathrm{ZnO}$ can be recovered at ambient conditions only when nanopowders of $\mathrm{w}-\mathrm{ZnO}$ are used as precursors [4]. Preparation of starting $\mathrm{w}-\mathrm{ZnO}$ nanopowders by methods of solution chemistry [4] does not allow synthesis of $\mathrm{ZnO}$ nanoparticles free of surface chemical groups that can strongly impact the heat capacity measurements and subsequent free energy calculations. Milling techniques also does not allow obtaining the samples of high crystal perfection for measurements of sufficient thermodynamic quality. To avoid any organic or inorganic impurity - except small amount of absorbed water-we synthesized $\mathrm{w}$ - $\mathrm{ZnO}$ nanopowder "precursor" by thermal decomposition of zinc peroxide $\mathrm{ZnO}_{2}$ (Prolabo, $70 \%$ of $\mathrm{Zn}$ in the form of $\left.\mathrm{ZnO}_{2}\right)$ in a muffle furnace in air at $570 \mathrm{~K}$ (120 min.). Nanoparticles with grain size of $10-50 \mathrm{~nm}$ can be clearly seen on the SEM image (Figure 1a). The X-ray diffraction pattern of the initial $\mathrm{w}-\mathrm{ZnO}$ powder shows lines broadening due to nanocrystallinity (Figure 1d). No diffraction peaks from $\mathrm{ZnO}_{2}$ or other crystalline impurities were detected. 


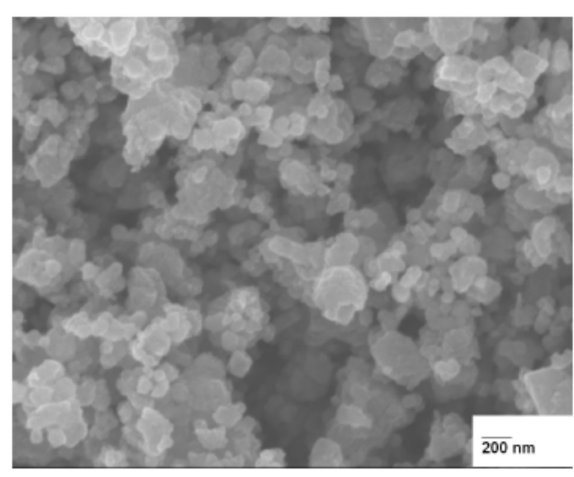

(a)

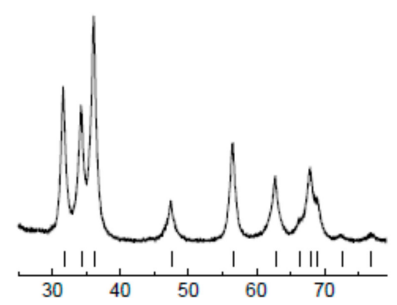

(d)

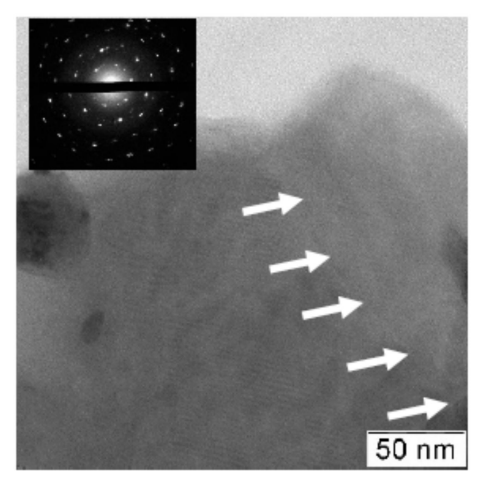

(b)

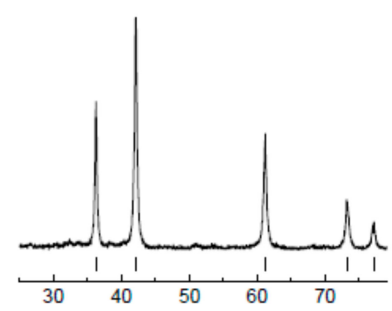

(e)

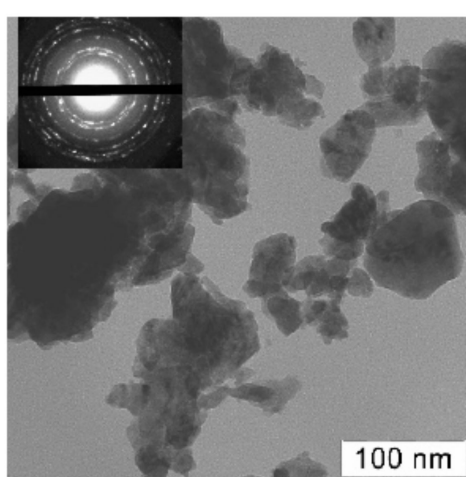

(c)

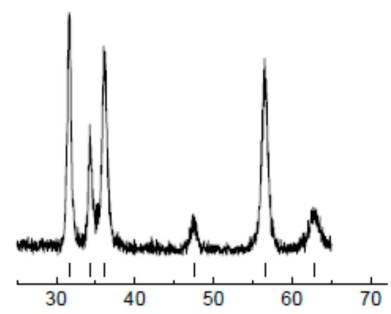

(f)

Figure 1. (a) SEM image of $\mathrm{w}-\mathrm{ZnO}$ particles obtained by thermal decomposition of $\mathrm{ZnO}_{2}$ that show morphology typical for nanopowders. (b) TEM image of rs-ZnO nanoparticles quenched from high pressure. Inset shows SAED pattern of rock salt structure. Arrows point to grain boundary. (c) TEM image of $\mathrm{w}-\mathrm{ZnO}$ nanoparticles prepared by thermal decomposition of rs-ZnO. Inset shows SAED pattern of wurtzite structure. (d-f) X-ray diffraction patterns (CuK $\alpha$ radiation) of pristine $\mathrm{w}-\mathrm{ZnO}$ nanopowder (d), synthesized $\mathrm{rs}-\mathrm{ZnO}(\mathbf{e})$, and $\mathrm{w}-\mathrm{ZnO}$ obtained by reverse phase transformation (f). Vertical bars indicate the Bragg peaks positions.

Single-phase nanocrystalline bulk (pellet $\sim 1 \mathrm{~mm}$ thickness and $4.5 \mathrm{~mm}$ in diameter) rs- $\mathrm{ZnO}$ has been synthesized from $\mathrm{w}-\mathrm{ZnO}$ nanopowder (grain size of $\sim 9 \mathrm{~nm}$ ) at $7.7 \mathrm{GPa} \&$ $800 \mathrm{~K}$ and subsequent rapid quenching (Figure $1 \mathrm{~b}$,e). The details of high-pressure synthesis and characterization of the recovered samples are described earlier $[4,5,7]$. Nanocrystalline bulk $\mathrm{w}-\mathrm{ZnO}$ obtained by reverse (from rs- $\mathrm{ZnO}$ to $\mathrm{w}-\mathrm{ZnO}$ ) phase transformation was used as reference sample (Figure 1c,f). This eliminates the potential influence of grain size and possible surface contribution to the heat capacity. The X-ray powder diffraction patterns taken before and after the calorimetric measurement confirmed that the samples were single-phases without any impurity. As one can see on the upper right part of the photo (Figure $1 \mathrm{~b}$ ) between rs- $\mathrm{ZnO}$ nanograins exist intergrain boundaries that could contain water molecules absorbed on the $\mathrm{w}$ - $\mathrm{ZnO}$ surface before the high-pressure synthesis. As follows from [4], this water probably plays the role of "glue" and helps to stabilize metastable rock salt phase at ambient pressure. Elimination of these water molecules will inevitably lead to reverse transformation to wurtzite phase.

$\mathrm{w}$-ZnO samples for $C_{p}$ measurements were obtained via reverse phase transformation of the corresponding rs-ZnO bulks by linear heating ( 5 or $10 \mathrm{~K} / \mathrm{min}$ ) at controlled conditions in a DSC-131 evo scanning calorimeter (SETARAM Instrumentation).

Heat capacity of rs-ZnO and w-ZnO bulk samples was measured between 310 and $2 \mathrm{~K}$ (Figure 2a, open symbols) using calibrated heater-thermometer platforms in Physical Property Measurement System apparatus by Quantum Design. Data at 40 different temperature points (two measurements per point) have been collected at constant helium pressure (35-60 $\times 10^{-2} \mathrm{~Pa}$ ) and in constant magnetic field (0.187 Oe) (Figure 2a). Before measurements, one side of each $\mathrm{ZnO}$ ingot was polished into a flat surface. Most of the measurements were performed on two cubic-shaped samples with $4.90 \mathrm{mg}(\mathrm{rs}-\mathrm{ZnO})$ and 
$13.80 \mathrm{mg}(\mathrm{w}-\mathrm{ZnO})$ weight. The $\mathrm{ZnO}$ molar weight of $81.38 \mathrm{~g} / \mathrm{mole}$ was used to molar $C_{p}$ calculation according to the 2011 IUPAC recommendation [8]. Recently, it has been shown that PPMS can precisely measure the low-temperature $C_{p}$ for samples of milligram size [9]. Thus, the low-temperature $C_{p}$ measurements of high-pressure phases, which were almost impossible to achieve previously, can now be carried out using this technique. The accuracy of $C_{p}$ measurement in our experiments was estimated to be better than $1 \%$ between $4.2 \mathrm{~K}$ and $315 \mathrm{~K}$, and $4 \%$ at temperatures below $4.2 \mathrm{~K}$.

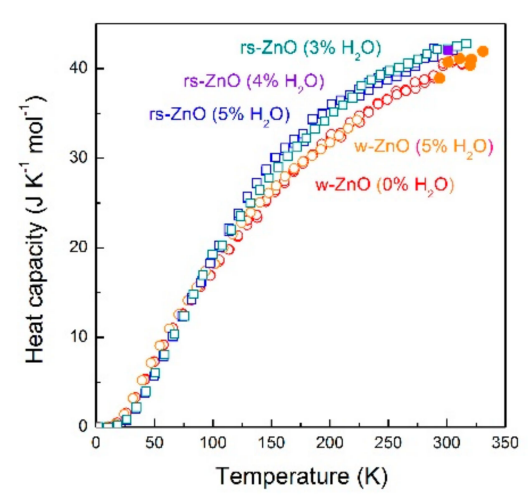

(a)

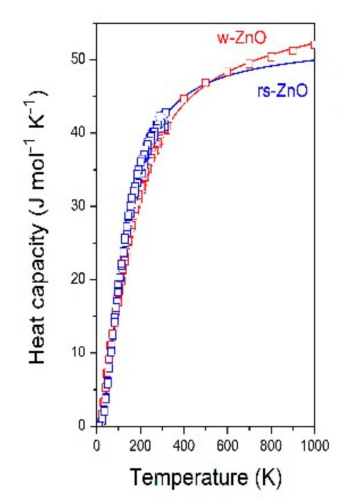

(b)

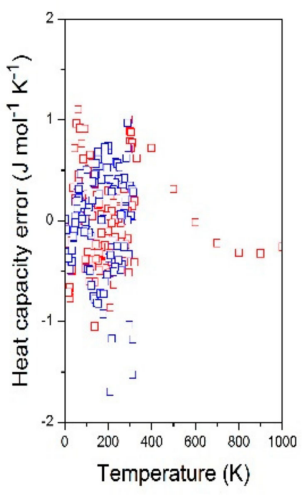

(c)

Figure 2. (a) Experimental heat capacities of nanostructured rs- $\mathrm{ZnO}$ (squares) and $\mathrm{w}-\mathrm{ZnO}$ (circles). Open symbols correspond to PPMS measurements, while solid symbols—to SETARAM calorimeter measurements. The size of symbols corresponds to the error estimate. (b) Heat capacity data fitted to Holtzapfel Equation (1). High-temperature extrapolation for $\mathrm{rs}-\mathrm{ZnO}$ has been made using regularized fitting procedure described in the text. Red and blue solid lines represent the calculated $C_{p}$ curves for $\mathrm{w}-\mathrm{ZnO}$ and $\mathrm{rs}-\mathrm{ZnO}$, respectively. Solid squares of the same color show experimental data. The size of squares corresponds to the error estimate. (c) Discrepancy between experimental and calculated values of heat capacities. Most of the data points are in within $\pm 0.5 \mathrm{~J} \mathrm{~mol}^{-1} \mathrm{~K}^{-1}$.

Heat capacity measurements in the 294-331 K range (Figure 2a, solid symbols) were performed by heat flux calorimetry using micro DSC-7 evo Calvet calorimeter (SETARAM Instrumentation). Dynamic calibration for heat generation was carried out by the Joule effect using a E.J.3 calibration unit. Temperature calibration of the instrument was performed with standard substances (gallium, indium, etc.) according to the IUPAC recommendations. Calisto program package (v 1.086, AKTS AG) was applied for running the experiment, data collection and initial data processing. Stepwise heating mode was used as recommended for precise thermodynamic measurements [10]. The accuracy of $C_{p}$ measurements was estimated to be better than $0.25 \%$.

Thermogravimetry measurements (Labsys evo TG/DSC thermal analyzer, SETARAM Instrumentation) were used for evaluation of the amount of absorbed water in the samples. Typically, the $\mathrm{H}_{2} \mathrm{O}$ loss was in the range of $2-4 \mathrm{wt} \%$. These values can be considered as an underestimate, while the heat capacity contribution shows the water amount of $\sim 5 \mathrm{wt} \%$ (this value should be taken with precaution since $C_{p}$ of absorbed water is higher than that of bulk water [11]). The correction to heat capacity has been made using the reference data for water in the 2-273 K and 273-310 K temperature ranges [12]:

$$
\begin{aligned}
\mathrm{H}_{2}{ }^{O} \mathrm{C}_{p}\left(\mathrm{~J} \mathrm{~mol}^{-1} \mathrm{~K}^{-1}\right)= & 18 \times\left(7.73 \times 10^{-3} \times \mathrm{T} \times\left(1-\exp \left(-1.263 \times 10^{-3} \times T^{2}\right)\right)-7.59 \times 10^{-3}+2.509 \times 10^{-3} \times T\right. \\
& \left.-1.472 \times 10^{-5} \times T^{2}-1.617 \times 10^{-9} \times T^{3}+8.406 \times 10^{-11} \times T^{4}\right) .
\end{aligned}
$$

\section{Results \& Discussion}

rs-ZnO samples available at ambient pressure are always nanostructured, and can survive only at quite moderate temperatures. Previous reports suggest possible impact 
of nanostructuring on $\mathrm{ZnO}$ heat capacity values. Our experiments, however, indicate that to the accuracy of the measurements, no difference between nanostructured $\mathrm{w}-\mathrm{ZnO}$ (obtained by reverse transformation of $\mathrm{rs}-\mathrm{ZnO}$ upon heating) and bulk $\mathrm{w}-\mathrm{ZnO}$ is observed. At the same time, samples exposed to air may show higher heat capacity, if absorbed water correction is not made. Typically, 3-5 wt\% of water was found as the equilibrium value for nano-rs- $\mathrm{ZnO}$, and both nano-and micro-w- $\mathrm{ZnO}$. Corrected values for rs- $\mathrm{ZnO}$ and $\mathrm{w}-\mathrm{ZnO}$ are shown in Figure 2a. No distinction between nano- and micro-samples will be made in the following discussion.

The experimental values of the heat capacity for $\mathrm{w}-\mathrm{ZnO}$ and $\mathrm{rs}-\mathrm{ZnO}$ nanostructured samples (Figure 2b) were fitted to the adaptive pseudo-Debye model proposed by Holtzapfel (explicitly formulated in [13]) that gives the analytical expression for $C_{p}$ as

$$
c_{p}=3 R \tau^{3} \frac{4 C_{0}+3 C_{1} \tau+2 C_{2} \tau^{2}+C_{3} \tau^{3}}{\left(C_{0}+C_{1} \tau+C_{2} \tau^{2}+C_{3} \tau^{3}\right)^{2}}\left[1+A \frac{\tau^{4}}{(a+\tau)^{3}}\right],
$$

where $\tau=T / \theta_{h} ; \theta_{h}$ is Debye temperature in the high-temperature region; $C_{1}, C_{2}$ and $A$ are parameters to be fitted; $C_{3}=1$; $a$ characterizes non-harmonicity; $R$ is gas constant. Parameter $C_{0}$ has been chosen as $C_{0}=\left(5 \theta_{l}^{3}\right) /\left(\pi^{4} \theta_{h}{ }^{3}\right)$, with $\theta_{l}$ and $\theta_{h}$ Debye temperatures in the low- and high-temperature regions, respectively, in order to obtain these values directly as fitting parameters.

The fitting of the experimental data to Equation (1) was performed using the simplex method using the MATLAB software. The uniqueness and stability of the solution (i.e., a set of above-mentioned parameters determining theoretical curve) of inverse problem have been tested by multiple minimization procedures from various sets of starting parameters. To improve the solution quality and obtain the parameters allowing high-temperature extrapolation, we added the available data on $C_{p}$ of $\mathrm{w}-\mathrm{ZnO}$ up to $1250 \mathrm{~K}$, which allowed obtaining the reliable values of $\theta_{h}, A$ and $a$. It was possible to exclude the mutual compensation of fitting parameters only in the case of $\mathrm{w}-\mathrm{ZnO}$ : the number and quality of the initial data combined with the $a$ value constrained to be positive and with taking into account the additional high-temperature data. In order to avoid occasional non-physical solutions for $\mathrm{rs}-\mathrm{ZnO}$, we used the $\mathrm{w}-\mathrm{ZnO}$ parameters as the initial approximation. For both phases, non-harmonicity parameter $a$ was found to be zero.

The fitting gave the following sets of parameters:

(1) for w-ZnO: $\theta_{h}=256 \mathrm{~K}, \theta_{l}=132 \mathrm{~K}, C_{0}=0.0070, C_{1}=0.4490, C_{2}=0.9942, A=0.0208$, $a=0$;

and

(2) for rs-ZnO: $\theta_{h}=226 \mathrm{~K}, \theta_{l}=335 \mathrm{~K}, C_{0}=0.1663, C_{1}=0.3864, C_{2}=0.9755, A=0.0055$, $a=0$.

One can see that the high-temperature limits of Debye temperature $\theta_{D}$ are close, while the low-temperature values are in agreement with the general rule that the higher density corresponds to higher Debye temperature. At the same time, our $\theta$-values are noticeably lower than the previously reported Debye temperatures ( 400 K) for w-ZnO [14]. Such discrepancy can be explained, from one side, by nanostructuring of our samples, and, from the other side, by the experimental errors that allow treating the $\theta_{l}$ values as fitting parameters. Only rigorous study of fully water-free samples could reveal whether nanostructuring impacts Debye temperature or not.

In the case of the nanostructured $\mathrm{w}-\mathrm{ZnO}$ obtained by reverse transformation from rs- $\mathrm{ZnO}$ at $523 \mathrm{~K}$, the heat capacity is quasi-indistinguishable from the large-grain samples. This is indicative of essentially zero surface entropy of our nano-w- $\mathrm{ZnO}$, similar to previous observations for nano- $\mathrm{w}-\mathrm{ZnO}$ obtained by chemical decomposition of zinc nitrate at 573 $\mathrm{K}$ [11]. Such closeness can be attributed to the thermal cure of the surface.

Figure 3a shows the formation enthalpy $\Delta H_{\mathrm{f}}$ calculated using the fitted values of heat capacities and experimental value of $\Delta H_{\mathrm{f}}(298.15 \mathrm{~K})=11.7 \pm 0.3 \mathrm{~kJ} \mathrm{~mol}^{-1}$ [6]. One can observe only weak temperature dependence of $\Delta H_{\mathrm{f}}$. The minimum and maximum 
on the curve are due to the double intersection of heat capacity curves of $\mathrm{w}-\mathrm{ZnO}$ and rs-ZnO nanostructured phases. These values differ by a factor of two from the results of indirect measurements at high temperatures (e.g., by EFM measurements [15]), which can be explained by the 1100-1300 K experimental range that is out of rs-ZnO stability region, as well as by the nanocrystallinity of our samples. It is also interesting to compare $\Delta H_{\mathrm{f}}$ values with the ab initio predictions (at $0 \mathrm{~K}$ ) that show a large dispersion (from 15 to $30 \mathrm{~kJ} \mathrm{~mol}^{-1}$ ) of calculated values, e.g., 21.230 and $28.950 \mathrm{~kJ} \mathrm{~mol}^{-1}$ (by LDA and GGA, respectively) in [16] and 15.247 and $22.871 \mathrm{~kJ} \mathrm{~mol}^{-1}$ (by LDA and GGA, respectively) in [17]. The variation of the calculated values by a factor of two does not allow making any reliable evaluation of thermodynamic stabilities of bulk phases at low temperatures. At the same time, the ab initio simulations of structural transition in $\mathrm{ZnO}$ nanowires at high pressures (calculations using the SIESTA code) indicated that passage from bulk crystal to nanograins reduces $\Delta H_{\mathrm{f}}(0 \mathrm{~K})$ from $23 \mathrm{~kJ} \mathrm{~mol}^{-1}$ down to $10 \mathrm{~kJ} \mathrm{~mol}^{-1}$ [18]. This result is consistent with the data in [6] and imply the difference between bulk- and nano-phase diagrams of $\mathrm{ZnO}$.

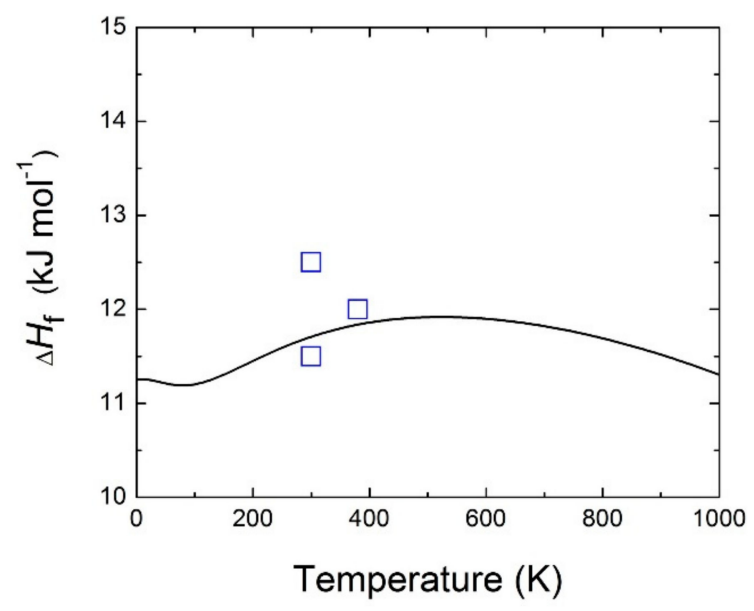

(a)

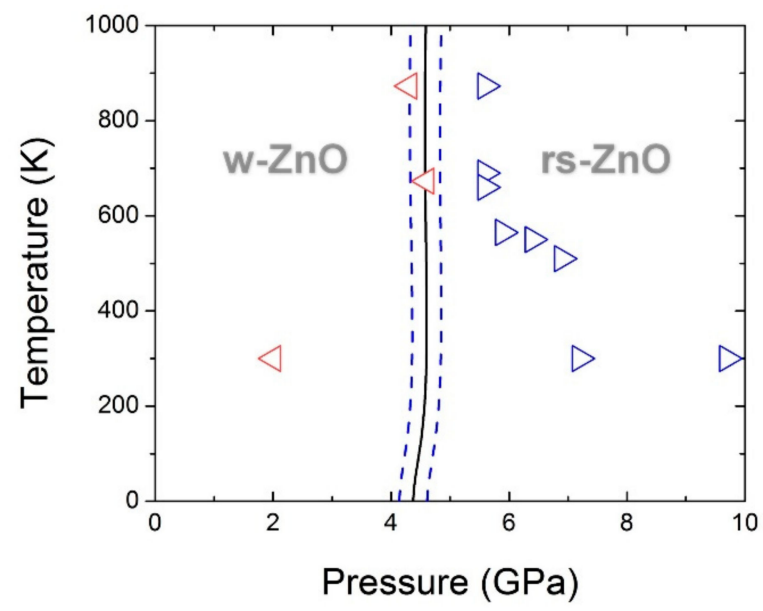

(b)

Figure 3. Calculated difference of formation enthalpies of $\mathrm{ZnO}$ polymorphs $\Delta H_{\mathrm{f}}(T)$ at $0.1 \mathrm{MPa}$, and $p$ - $T$ phase diagram (i.e., $\left.\Delta G_{\mathrm{rs} / \mathrm{w}}(p, T)=0\right)$ vs. experimental and ab initio data. (a) Black solid line is $\Delta H_{\mathrm{f}}$ as a function of temperature extrapolated to $1000 \mathrm{~K}$ using regularized procedure described in the text; blue open squares are experimental data from [6]; (b) Nano-phase diagram of $\mathrm{ZnO}$ representing equilibria between nanostructured phases. Isopotential curve corresponds to $\Delta G_{\mathrm{rs}} / \mathrm{w}(p, T)=0$ (equilibrium between $\mathrm{w}-\mathrm{ZnO}$ and $\mathrm{rs}-\mathrm{ZnO}$; black solid line) with the estimated error of $\pm 0.3 \mathrm{~kJ} \mathrm{~mol}^{-1}$ for $\Delta H_{\mathrm{f}}[6]$ (the dashed blue lines). Symbols represent experimental $p, T$-points on direct (right-oriented red triangles) and inverse (left-oriented blue triangles) transformations observed by in situ X-ray diffraction [7,19].

Nano-phase diagram of zinc oxide has been calculated using the fitted experimental heat capacity values, directly-measured $\Delta H_{\mathrm{f}}[6]$ and thermoelastic $p-V-T$ data on rs$\mathrm{ZnO}[5,19]$ and $\mathrm{w}-\mathrm{ZnO}$ [20]. The experimental data on direct and inverse transformations in $\mathrm{ZnO}$ at high (above $500 \mathrm{~K}$ ) temperatures are in satisfactory agreement [7,19]. At lower temperatures, where the transformation hysteresis is pronounced, the application of the estimated $p_{e q}$ for the equilibrium pressure as shown in Eq. 2 results in the $p_{e q}$ value of $5 \pm 3 \mathrm{GPa}$ at $300 \mathrm{~K}[19,21]$. The uncertainties have an order of magnitude of the yield stress accumulated during the transformation [22]. Here, we should note that the use of the hypothesis that $p_{e q} \approx p_{\text {direct }}$ is methodologically incorrect. In fact, both direct and inverse transformations were observed experimentally at finite pressure, which is in agreement with Landau character of 2nd-order transformation driven by the lattice strain as order parameter. Such model requires the onset pressure of $\sim 9.4 \mathrm{GPa}$ [22] above the equilibrium corresponding to the formal requirement of $\Delta G_{\mathrm{rs} / \mathrm{w}}(p, T)=0$.

$$
p_{\text {eq }} \approx 0.5 \times\left(p_{\text {direct }}+p_{\text {inverse }}\right)
$$




\section{Conclusions}

The low-temperature $(2-310 \mathrm{~K})$ isobaric heat capacities of rock salt $\mathrm{ZnO}$, metastable high-pressure phase and wurtzite $\mathrm{ZnO}$ have been experimentally studied using the thermal relaxation PPMS calorimetry. Measurements of low-temperature heat capacities of nanostructured $\mathrm{ZnO}$ polymorphs and analysis of the equation-of-state data allowed us to resolve the ambiguities of the equilibrium $p$ - $T$ phase diagram of $\mathrm{ZnO}$. A set of proposed thermo-physical data is well consistent with the observed direct and inverse phase transformations in nanostructured $\mathrm{ZnO}$ up to $1000 \mathrm{~K}$. In this temperature range, the equilibrium pressure is close to $4.6 \mathrm{GPa}$, which is lower than the ab initio prediction for bulk $\mathrm{ZnO}$, but in a good agreement with simulations made for nanoparticles.

Author Contributions: Conceptualization, V.L.S. and A.C.; methodology, A.C. and V.L.S.; investigation, K.V.K., P.S.S., A.N.B., F.Y.S. and V.L.S.; data curation, K.V.K., A.C. and V.L.S.; writingoriginal draft preparation, A.C.; writing-review and editing, V.L.S.; visualization, A.C.; supervision, V.L.S.; funding acquisition, V.L.S. All authors have read and agreed to the published version of the manuscript.

Funding: This research was funded in part by the Russian Foundation for Basic Research, grant number 11-03-01124.

Institutional Review Board Statement: Not applicable.

Informed Consent Statement: Not applicable.

Acknowledgments: P.S.S. is thankful to the "Science and Engineering for Advanced Materials and devices" (SEAM) Laboratory of Excellence for financial support. A.N.B. is grateful to the Université Sorbonne Paris Cité for financial support.

Conflicts of Interest: The authors declare no conflict of interest.

\section{References}

1. Kurakevych, O.O.; Le Godec, Y.; Hammouda, T.; Goujon, C. Comparison of solid-state crystallization of boron polymorphs at ambient and high pressures. High Press. Res. 2012, 32, 30-38. [CrossRef]

2. Solozhenko, V.L.; Kurakevych, O.O.; Le Godec, Y.; Brazhkin, V.V. Thermodynamically Consistent p-T Phase Diagram of Boron Oxide B2O3 by in Situ Probing and Thermodynamic Analysis. J. Phys. Chem. C 2015, 119, 20600-20605. [CrossRef]

3. Klingshirn, C.; Fallert, J.; Zhou, H.; Sartor, J.; Thiele, C.; Maier-Flaig, F.; Schneider, D.; Kalt, H. 65 years of ZnO research—Old and very recent results. Phys. Status Solidi B 2010, 247, 1424-1447. [CrossRef]

4. Baranov, A.N.; Sokolov, P.S.; Tafeenko, V.A.; Lathe, C.; Zubavichus, Y.V.; Veligzhanin, A.A.; Chukichev, M.V.; Solozhenko, V.L. Nanocrystallinity as a Route to Metastable Phases: Rock Salt ZnO. Chem. Mater. 2013, 25, 1775-1782. [CrossRef]

5. Sokolov, P.; Baranov, A.; Bell, A.; Solozhenko, V. Low-temperature thermal expansion of rock-salt ZnO. Solid State Commun. 2014, 177, 65-67. [CrossRef]

6. Sharikov, F.Y.; Sokolov, P.S.; Baranov, A.N.; Solozhenko, V.L. On the thermodynamic aspect of zinc oxide polymorphism: Calorimetric study of metastable rock salt ZnO. Mendeleev Commun. 2017, 27, 613-614. [CrossRef]

7. Solozhenko, V.L.; Kurakevych, O.O.; Sokolov, P.S.; Baranov, A.N. Kinetics of the Wurtzite-to-Rock-Salt Phase Transformation in $\mathrm{ZnO}$ at High Pressure. J. Phys. Chem. A 2011, 115, 4354-4358. [CrossRef] [PubMed]

8. Wieser, M.E.; Holden, N.; Coplen, T.B.; Böhlke, J.K.; Berglund, M.; Brand, W.A.; De Bièvre, P.; Gröning, M.; Loss, R.D.; Meija, J.; et al. Atomic weights of the elements 2011 (IUPAC Technical Report). Pure Appl. Chem. 2013, 85, 1047-1078. [CrossRef]

9. Kennedy, C.A.; Stancescu, M.; Marriott, R.A.; White, M.A. Recommendations for accurate heat capacity measurements using a Quantum Design physical property measurement system. Cryogenics 2007, 47, 107-112. [CrossRef]

10. Wendlandt, W.W. Thermal Analysis, 3rd ed.; John Wiley \& Sons: New York, NY, USA, 1986.

11. Ma, C.; Shi, Q.; Woodfield, B.F; Navrotsky, A. Low temperature heat capacity of bulk and nanophase $\mathrm{ZnO}$ and $\mathrm{Zn} 1-\mathrm{xCoxO}$ wurtzite phases. J. Chem. Thermodyn. 2013, 60, 191-196. [CrossRef]

12. Giauque, W.F.; Stout, J.W. The Entropy of Water and the Third Law of Thermodynamics. The Heat Capacity of Ice from 15 to 273 ${ }^{\circ}$ K. J. Am. Chem. Soc. 1936, 58, 1144-1150. [CrossRef]

13. Solozhenko, V.L.; Turkevich, V.Z.; Holzapfel, W.B. Refined Phase Diagram of Boron Nitride. J. Phys. Chem. B 1999, 103, $2903-2905$. [CrossRef]

14. Madelung, O.; Rössler, U.; Schulz, M. (Eds.) Zinc oxide (ZnO) Debye temperature, heat capacity, density, melting point, vapor pressure, hardness: Datasheet from Landolt-Börnstein—Group III Condensed Matter Volume 41B: "II-VI and I-VII Compounds; Semimagnetic Compounds". In Springer Materials; Springer: Berlin/Heidelberg, Germany, 1999. 
15. Kachhawaha, J.; Tare, V. Electrochemical determination of free energy changes of allotropic transformation of ZnO. Solid State Ionics 1981, 5, 575-578. [CrossRef]

16. Molepo, M.P.; Joubert, D.P. Computational study of the structural phases of ZnO. Phys. Rev. B 2011, 84, 094110. [CrossRef]

17. Jaffe, J.E.; Snyder, J.A.; Lin, Z.; Hess, A.C. LDA and GGA calculations for high-pressure phase transitions in ZnO and MgO. Phys. Rev. B 2000, 62, 1660-1665. [CrossRef]

18. Gao, Z.; Gu, Y.; Zhang, Y. First-Principles Studies on the Structural Transition of ZnO Nanowires at High Pressure. J. Nanomater. 2010, 2010, 462032. [CrossRef]

19. Decremps, F.; Zhang, J.; Liebermann, R.C. New phase boundary and high-pressure thermoelasticity of ZnO. EPL Europhys. Lett. 2000, 51, 268-274. [CrossRef]

20. Desgreniers, S. High-density phases of ZnO: Structural and compressive parameters. Phys. Rev. B 1998, 58, 14102-14105. [CrossRef]

21. Kusaba, K.; Syono, Y.; Kikegawa, T. Phase transition of ZnO under high pressure and temperature. Proc. Jpn. Acad. Ser. B 1999, 75, 1-6. [CrossRef]

22. Kulkarni, A.; Sarasamak, K.; Wang, J.; Ke, F.; Limpijumnong, S.; Zhou, M. Effect of load triaxiality on polymorphic transitions in zinc oxide. Mech. Res. Commun. 2008, 35, 73-80. [CrossRef] 